Den 7. März zur Zeit dieser Beobachtung war der Komet genau im Parallel des 30sten im Teleskop Bode Cat. 1301 von Lalande bestimmt nit

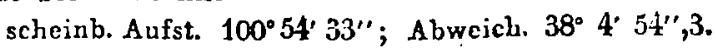

$W$ ir verglichen ihn mit 257 Fuhrmann, und erhielten scheinb. Aufst. $100^{\circ} 54^{\prime} 2^{\prime \prime}$; Also $38^{\circ} 7^{\prime} 57^{\prime \prime}$

$$
-31 \text { Untersch. }+33 \text {. }
$$

Den 23. März war es nicht ganz heiter, der Komet sehr scliwer zu beobachten.

Den 7. März sah er aus, wie ein kaum bemerkbarer unförmiger Dunst, den man nicht für den Kometen hätte halten kömnen, wäre nicht sein Ort beynahe bekannt gewesen.

Die anhaltende üble Witterung gestattete nur den 10. Fehriar die Beobachtung folgender Moudsterne am Mittagsrohr in Sternzeit.

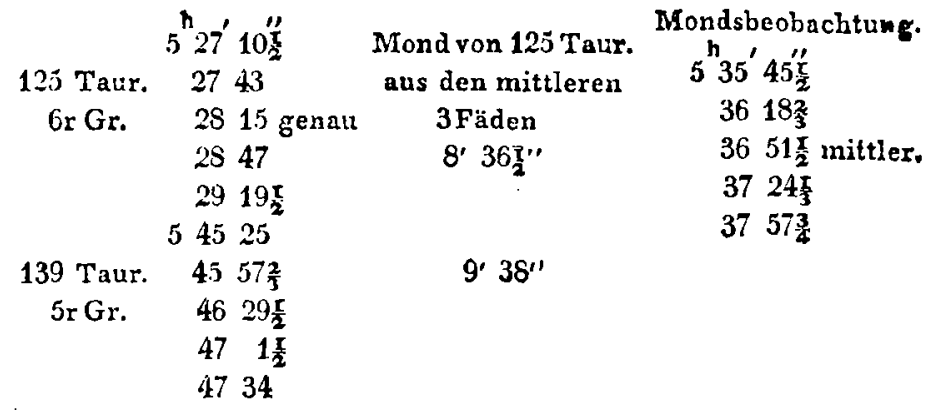

Anmerk. Die Kometenbeohachtungen sind mit einem lichtstarken 7 fürs. Dollond angestellt, der mit einem Rautenmikrometer aus Mes. sing versehen ist.

$D a v i d$

\title{
Länge der Prager Sternwarte geprüft durch geodätische Vermessungen.
}

Der o̊sterr. Generalstaab fand mit seinen Dreyeckvermessungen den Lorenzberg bey Prag westlicher, als den Stephansthurm in Wien 74601,457 Wiener Klafter. 110946,557 W. Kl. nördlicher.

Mit der Breite des Stephansthurm $48^{\circ} 12^{\prime} 34^{\prime \prime}$, und Länge $34^{\circ} 2^{\prime} 16 \frac{T^{\prime \prime}}{2}$ herechnete Herr Oberst Richter des Generalstaabes fïr den Lorenzberg bey Prag die Breite $50^{\circ} 5^{\prime} 5^{\prime \prime}, 79$ (wahrsch. mit ${ }_{3}^{\frac{x}{0}}$ Abplattung) Lange $\quad 32335,25$

$\mathrm{Nach}_{3}$ meiner trigonometrischen Vermessung zur Verbindung der Sternwarte mit dem Lorenzberg ist dieser 12" 8? siidlicher, 1' $13 \frac{27}{100}$ westlicher.

Daraus der Sternwarte Breite $50^{\circ} 5^{\prime} 18^{\prime \prime}, 66$

$$
\text { Länge } 32 \quad 4 \quad 45,52
$$

Stephansthurm zu Wien Länge 34216,5

$$
\text { Unterschied } 15798 \text { in Zeit } 7^{\prime} 49^{\prime \prime}, 9
$$

Bogenhausen von Paris in Zeit $37^{\circ} 5^{\prime \prime}$ A. N. Nr. 45 . S. 402.

Bogenhausen von Wien $-19 \quad 5,2-N$ N.24. S. 459.

Wien von. Paris 50.

Stephansthurm von Prag $\quad-\frac{749,9}{4520,3}$
Herr Lambert Mayer, Assistent an der Wiener Strenwarte, berechnete aus den letzten Sternbedeckungen Prag von Paris $48^{\prime} 20^{\prime \prime}, 36$. Diese Länge bestätiget die aus der Bedeckung des $\alpha$ Taur. 1792, wo ich beym Ein - und Austritte auf $\frac{1}{2}$ Zeitsekunde versichert war, und die Zeit aus korrespondirenden Sonnenhöhen richtig bestimmt habe.

Die Breite ron Prag fand ich mit verschiedenen Höhenmessern aus Scheitelabständen solcher Sterne, wo die Strahlenbrechung klein ist, vorzïglich durch den Polarstern: $50^{\circ} \overline{0}^{\prime} 18 \frac{1}{2}{ }^{\prime \prime}$.

Astron. Nachr. Bd. I. S. 435.

Astron. Beobachtungen von 1830-21 au der Práger Sternwarte im Bten Bande S.75. der k. bühm. Gesellschaft der Wissenschraften.

Geht man mit Herrn Wurm von der Länge der Wiener Sternwarte yon Paris 56' 10',3 aus (Nr. 45. S. 404.); und zieht den astronomisch bestimmten Unterschied ron Wien bis Prag $7^{\prime} 50^{\prime \prime}$ ab; so erhält man wieder Prag von Paris $48^{\prime} 20^{\prime \prime}, 3$.

Prag 1824. März 18.

$D a v i d$

\section{I $\quad$ n $h$ a. $\mathbf{l}$ t.}

Anszug aus einem Briefe des Herrn Brinkley, Directors der Dubliner Sternwarte, an den Herausgeber. p. 105̆.

Schreiben des Herrn Professors Encke an den Herrn Dr. Olbers in Bremen. p. 107.

Auszug aus einem Briefe des Herrn Prof. Nicolai an Herrn Hansen. p. 109.

Kreismikrometer-Beobachtungen des Cometen von 1823-24 auf der Mannheimer Sternwarte. p. 111.

Auszug aus einem Briefe des Herrn Prof. Encke an den Herausgeber. p. 113.

Brief des Herrn Professors Littrow an den Heransgeber. p. 113.

Cometenbeobachtungen auf der Prager Sternwarte vom 31. Decbr. 1823 bis 7. März 1824. p. 117.

Länge der Prager Sternwarte geprüft durch geodätische Vermessungen. p. 119. 